\title{
Study on Logistics Industry Development Policy of Beijing Based on System Dynamic
}

\author{
Shuihai Dou, Xuemei Li, Xuewei Li, Juanqiong Gou \\ Beïing Jiaotong University (China) \\ 09120784@,bjtu.edu.cn,xmli@bjtu.edu.cn,xwli@,bjtu.edu.cn,jggou@,bjitu.edu.cn
}

\section{Abstract:}

Purpose: This paper is committed to design a logistics industry development policy model based on system dynamic to simulate the policy measures which promote region economic and logistics efficiency. The interaction between logistic industry development policy and economy needs to be investigated and the influence degree of logistic efficiency affected by industry policy needs to be identified too.

Design/methodology/approach: In order to achieve the objective, it makes a system analysis from industry perspective to divide system into economic growth subsystem, logistics demand subsystem and logistics supply subsystem. Then the hypothesis and the boundaries are defined, and the causal diagram and system flow diagrams are drawn. The paper designs parameters and structural equation by the sample of Beijing using the econometrics model and takes model validation. Taking Beijing as an example, logistics industry development policy is simulated from the aspect of technological progress, increasing fixed assets investment, adjusting the industrial structure proportion and comprehensive policy by changing the parameters using Vensim-PLE.

Findings: After logistics development policy is highly simulated by system dynamic model of logistics industry development policy, it is found that the policies of technological progress, fixed assets investment increasing, the industrial structure proportion adjustment and the 
comprehensive policy have different function to affect GDP, logistics demand, supply capacity and actual logistics costs.

Originality/value: Compared with the previous research, this paper analyzes the interactive mechanism between logistics industry policy and region economy from a system perspective and establishes system dynamics model of logistics industry development policy to make up for the limitation of previous research.

Keywords: logistics industry, system dynamics, regional economy, policy proposal

\section{Introduction}

In the new economic situation, the rapid development of the logistics has gradually changed into the concept of an industry. It plays a pillar industry role in the national and regional economic development. Revealing the mechanism of logistics industry and regional economy development and proposing some countermeasures and suggestions will have a very important significance for the logistics industry development, regional economy and social progress.

In the past few years, issues of logistics industry development policy have come into eyes of domestic and foreign scholars. From the research level, logistics industry development policy can be classified into national and region level (Hai, Zhang \& Sun, 2005; Hens, Robvan \& Hei, 2011; Masahiro, 2010; Pilar, González, Adenso \& Hakim, 2004). From the national level, they have put forward logistics policies to promote economy in the point of macroeconomic (Magnus \& Ruth B., 2010). For example, Muñuzuri, Cortés, Guadix and Onieva,(2012) indicated that outdated logistics policy and regulations enforcement resulted in the urban logistics inefficient. Based on this, he proposed the development suggestions for city logistics of Spain. From regional level, domestic and foreign scholars proposed the logistics policy in accordance with the specific regional conditions (Jin, 2012; Liu, Li, Dai \& Zhang, 2013). Take Dilek (2012) as an example, he brought forth some suggestions for Istanbul logistics development on the base of its location advantages. According to the current situation of logistics in Hebei province, $\mathrm{Li}, \mathrm{Hu}$ and Meng (2009) proposed logistics strategy for Hebei province from aspects of formulating regional logistics service plan, building logistics parks, developing modern logistics enterprises and establishing logistics hardware and software. Throughout the views of all the scholars above, from the research content, all the scholars proposed the specific measures for logistics industry based on the actual situation. However, the specific implementation effect could not be determined. From the research methods, the qualitative methods rather than the quantitative methods were used to study the logistics industry development policy, which turned out that implementation effect of policy wasn't evaluated. 
Based on the above research status, this paper analyzes the interactive mechanism between logistics industry and region economy from a macro point and establishes system dynamics model of logistics industry development policies. Subsequently, logistics industry development policies of Beijing are simulated by collecting the data from 1978 to 2008 in Vensim-PLE (Wang, 2009). We expect that the simulation results can serve relevant department when they formulate logistics industry development policy.

\section{Logistics Industry Development Policies Model}

\subsection{System Analysis and Boundary Determination}

By summarizing the previous research results, the system dynamic model in this paper includes three subsystems.

Economic growth subsystem. There are so many economic and environmental factors affecting the regional economic development. In order to simplify the model, this paper considers that regional economy is only affected by the economy growth and the amount of logistics hinder.

Logistics demand subsystem. Logistics demand is the space, time and cost requirements for goods which are produced by social and economic activities configuring raw materials, finished and semi-finished products, goods and waste materials etc. within a certain period of time, including transportation, repertory, packaging, loading and unloading, distribution as well as many aspects of logistics activities like related information needs (Cao \& Chen, 2012). In this paper, logistics demand is the sum of the logistics demands from primary industry, second industry and tertiary industry.

Logistics supply subsystem. Logistics supply is an important concept corresponding with logistics demand. Logistics supply refers logistics service amounts which are provided by logistics business at a certain price. Logistics supply capacity lies on the amount of supply increase and supply consumption. On one hand, the amount of supply increase derives from government input including logistics infrastructure, logistics technology. On the other hand, logistics companies invest constantly to improve the logistics supply capacity so as to get development. Considering the data available, this paper mainly studies the government investment in logistics infrastructure. Logistics consumption can hinder logistics supply capacity owing to the gradual aging of the logistics infrastructure and logistics tool. In this paper, the consumption coefficient can be used to reflect the logistics consumption. 


\subsection{Causal Relationship Analysis}

The causal relationship is a qualitative description about the internal structure relationship of system, which is the basis of the system dynamics modeling. Therefore, by summarizing the previous research results and analyzing the relationship between the logistics industry development policy and regional economy, the causal diagram of logistics industry development policy can be established. The diagram is shown in Figure 1. Analyzing Figure 1, this system dynamic model includes the following basic feedback loops.

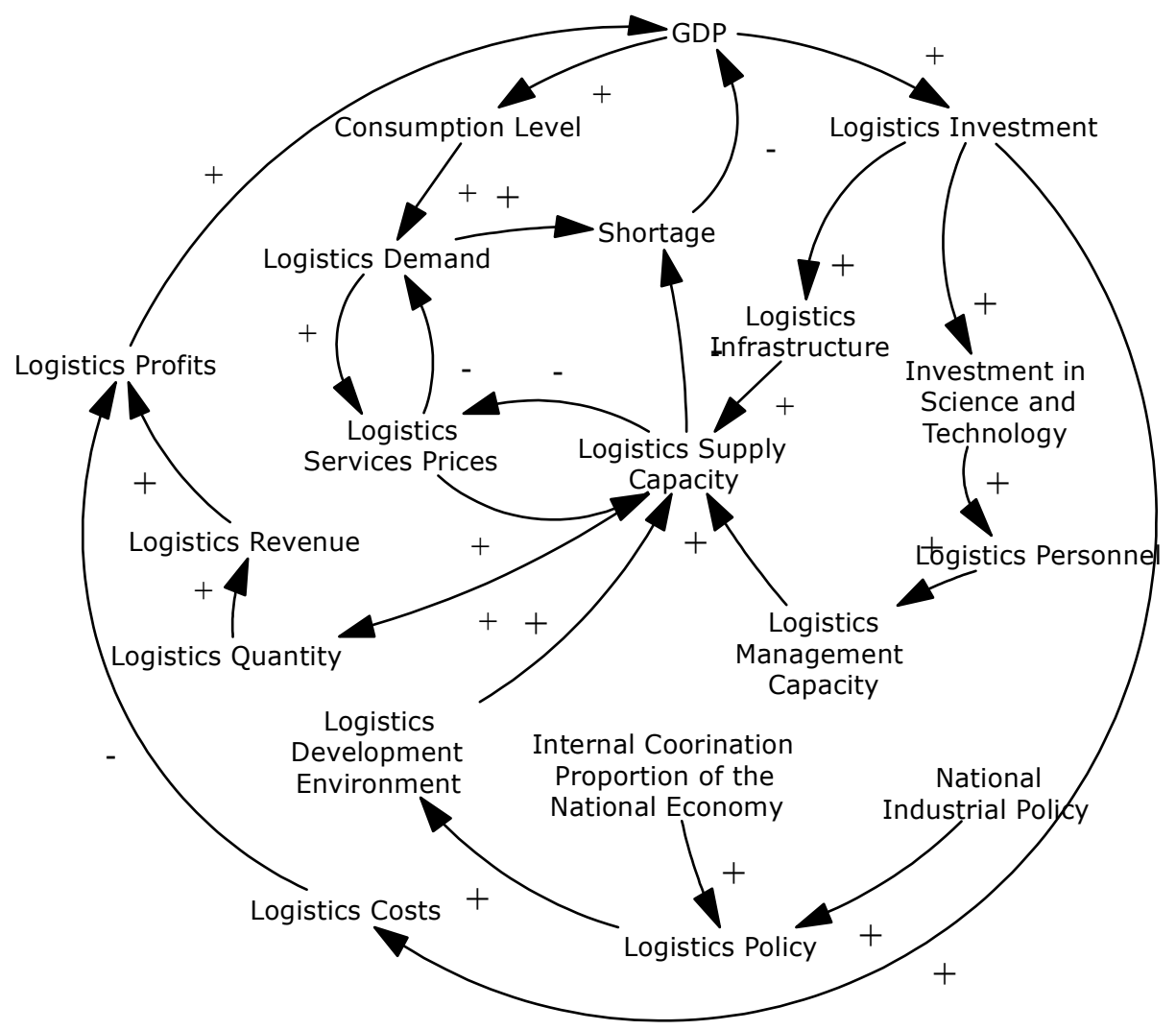

Figure 1. Basic Diagram of Regional Logistics Industry Development

(1) Feedback loop I: GDP $\rightarrow$ Consumption Level $\rightarrow$ Logistics Demand $\rightarrow$ Logistics Services Prices $\rightarrow$ Logistics Supply Capacity $\rightarrow$ Logistics Quantity $\rightarrow$ Logistics Revenue $\rightarrow$ Logistics Profits. This loop demonstrates that the improvement of the regional GDP will increase the urban residents' consumption level and the logistics market demand. Increasing logistics need will increase the logistics service price and logistics supply capacity, which makes the logistics industry develop rapidly and promotes the national economy in the end.

(2) Feedback loop II: GDP $\rightarrow$ National Industrial Policy $\rightarrow$ Logistics Investment $\rightarrow$ Logistics Infrastructure $\rightarrow$ Logistics Supply Capacity $\rightarrow$ Logistics Quantity $\rightarrow$ Logistics Profits. This loop demonstrates that government will increase investment in the logistics industry when making industry policies according to the increase of GDP. Logistics input raises the logistics supply 
capacity, and the supply capacity will enhance performance capacity, strengthen logistics industry revenue and drive GDP subsequently.

(3) Feedback loop III: GDP $\rightarrow$ Logistics Investment $\rightarrow$ Logistics Costs $\rightarrow$ Logistics Profits. It means when the regional GDP increases, government will increase investment in the logistics industry, but the investment will increase the logistics cost and reduces the profits of the logistics and the local GDP correspondingly.

(4) Feedback loop IV: GDP $\rightarrow$ Logistics Investment $\rightarrow$ Logistics Costs $\rightarrow$ Logistics Profits. It indicates regional GDP improvement will increase the logistics demand. If the logistics supply capacity isn't strengthened, the logistics demand would not be met, which will hinder the economy development.

(5) Feedback loop V: GDP $\rightarrow$ Logistics Investment $\rightarrow$ Logistics Supply Capacity $\rightarrow$ Logistics Shortage. This loop refers when the regional GDP increases, the government will increase investment in the logistics industry, thus enhancing the supply capacity and alleviating the shortages, which has a positive effect on the national economy.

\subsection{System Flow Diagram}

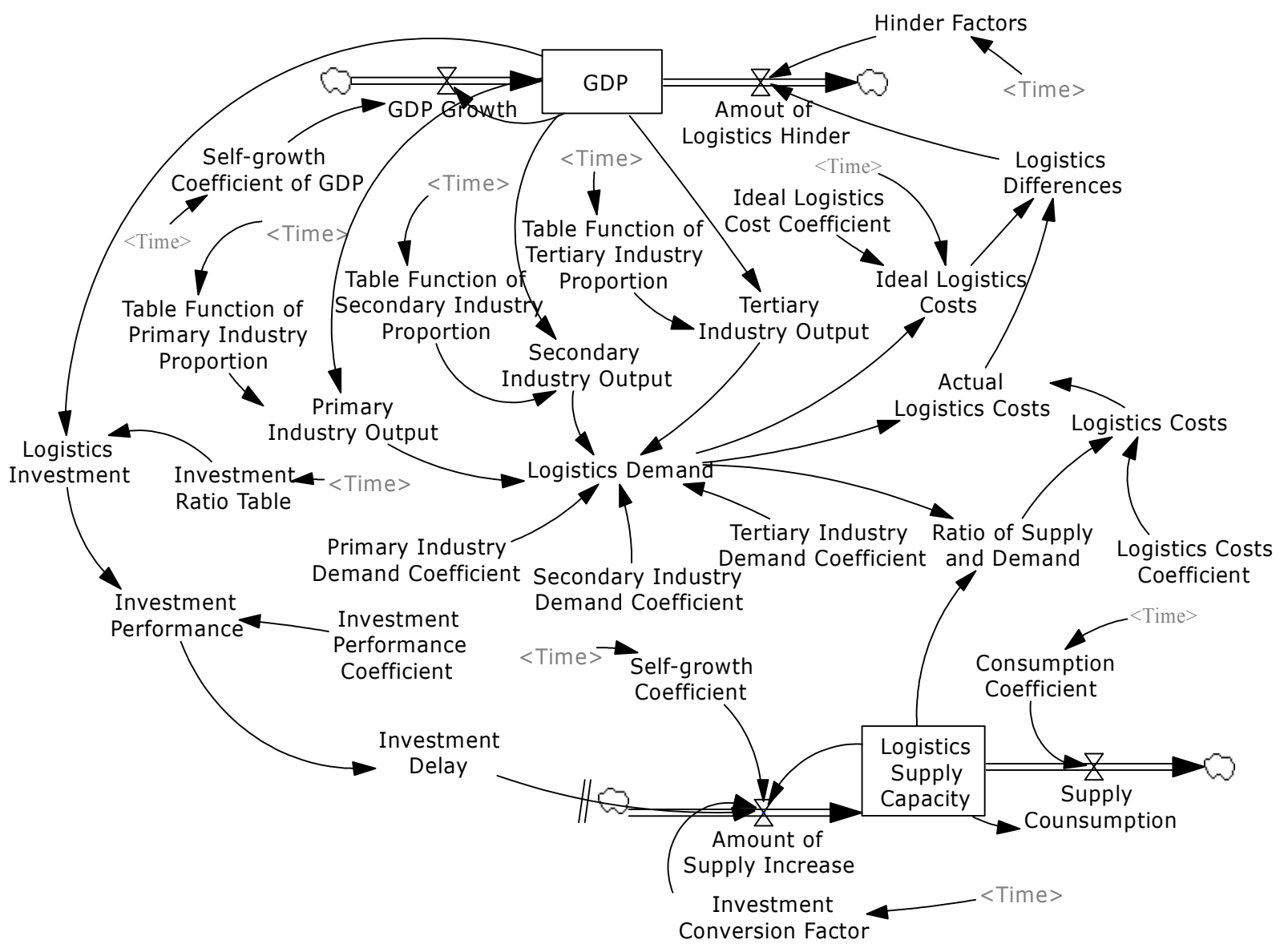

Figure 2. System Flow Diagram 
According to the causal diagram, the flow diagram of logistics industry development policy can be drawn, which is shown in Figure 2. There are two state variables including GDP and logistics supply capacity and the corresponding rate variables are the GDP growth increment, logistics hinder weight, supply increment and supply consumption amount. Auxiliary variables include logistics investment, investment results, investment delay, the ideal logistics costs, the actual logistics costs, primary industry output, secondary industry output and tertiary industry output. Constants include the demand coefficient of primary industry, secondary industry and tertiary industry. The table functions include the self-growth coefficient of GDP, primary industry table function, secondary industry table function, tertiary industry table function, investment ration table, consumption coefficient, and conversion coefficients of investment and hinder factor table etc.

\subsection{Major Structure Equations}

\section{(1) Economic growth subsystems}

According to the above system flow diagram, the equation of GDP state variable is shown in Equation 1.

$$
G D P_{t}=G D P_{t-1}+\int_{t-1}^{L}(G G-L H) d t
$$

In the Equation 1, GDP cumulates over time $(t)$, and the initial value is $G D P_{0}$, the cumulative value is the difference between GDP growth (GG) and logistics hinder (LH). In the Equation 2 and 3, the GG and the LH are the rate variables. GG can be expressed by the product of the GDP at the $t-1$ time and the GDP growth coefficient (GGC) at the $t-1$ time. Logistics hinder refers to the product of the logistics difference $L_{\text {difference( } t)}$ at the time $t$ and the hinder coefficient (HC) at the $t-1$ time. GDP growth coefficient (GGC) can be denoted by the table functions of GGC and time, as shown in Equation 4.

$$
\begin{gathered}
G G_{t}=G D P_{t-1} \times G G C_{t} \\
L H_{t}=L_{\text {difference }(t)} \times H C_{t} \\
G G C_{t}=G G C_{t}(\text { Time })
\end{gathered}
$$

The logistics difference (LD) is affected by the actual logistics costs ( $A L C$ ) and the ideal logistics costs (ILC). So the LD can be expressed by the difference of ALC and ILC, which is 
shown in Equation 5. ILC is affected by logistics demand $\left(L_{\text {demand }(t)}\right)$ and ideal logistics cost coefficient $\left(I L C C_{t}\right)$, thus the rate equation is shown in Equation 6.

$$
\begin{gathered}
L D_{t}=A L C_{t}-I L C_{t} \\
I L C_{t}=I L C C_{t} \times L_{\text {demand }(t)}
\end{gathered}
$$

The primary industry output value (PIO), the second industry output value (SIO) and the tertiary industry output value (TIO) are affected separately by the proportion of the primary industry (PPI), the proportion of the second industry (PSI) and the proportion of the tertiary industry (PTI). The rate equation of PIO, SIO and TIO are shown in Equations 7, 8 and 9. PPI, PSI and PTI can be expressed by the table functions which are shown in Equations 10, 11 and 12.

$$
\begin{gathered}
P I O_{t}=G D P_{t} \times P P I_{t} \\
S I O_{t}=G D P_{t} \times P S I_{t} \\
T I O_{t}=G D P_{t} \times P T I_{t} \\
P P I_{t}=P P I(\text { Time }) \\
P S I_{t}=P S I(\text { Time }) \\
P T I_{t}=P T I(\text { Time })
\end{gathered}
$$

\section{(2) Logistics demand subsystem}

Logistics demand ( $L_{\text {demand }}$ ) is affected by PIO, SIO, TIO, PIDC, SIDC and TIDC, therefore the multiple linear regression model of logistics demand can be established, which is shown in Equation 13.

$$
L_{d e m a n d(t)}=P I D C \times P I O_{t}+S I D C \times S I O_{t}+T I D C \times P T I_{t}+u
$$

As shown in Equation 14, the actual logistics cost (ALC) is influenced by the logistics demand ( $L_{\text {demand }}$ ) and logistics cost (LC). As shown in Equation 15, LC is affected by the logistics cost 
factor (LCF) and supply and demand ratio (SDR). SDR is the function of logistics supply capacity (LSC) and $L_{\text {demand, }}$ which is expressed by Equation 16.

$$
\begin{gathered}
A L C_{t}=L_{\text {demand }(t)} \times L F_{t} \\
L C_{t}=L C F_{t}\left(S D R_{t}\right) \\
S D R_{t}=\frac{L S C_{t}}{L_{\text {demand } t)}}
\end{gathered}
$$

\section{(3) Logistics supply subsystem}

In the system flow diagram, the equation of the LSC, supply increase (SI) and supply consumption (SC) are shown in Equations 17, 18 and 19.

In the Equation 17, LSC cumulates over time, and the initial value is $L S C_{0}$. The cumulative value is the difference between supply increased value (SI) and supply consumption (SC). As is shown in Equation 18, SI is the function of self-growth factor (SGF), investment delay (ID), LSC and investment conversion factor (ICF). As shown in Equation 19, the SC is the table function of consumption coefficient (CC) and Time, SGF and CC is expressed by the time function, which is shown in Equations 20 and 21. There is some delay from the logistics investment to logistics supply. It is found that three years delay has the best performance by co-integration analysis. The investment delay equation is shown in Equation 22.

$$
\begin{gathered}
L S C_{t}=L S C_{t-1}+\int_{t-1}^{t}(S I-S C) d t \\
S I_{t}=S F C_{t} \times L S C_{t}+I D_{t} \times I C F_{t} \\
S C_{t}=L S C_{t} \times C C_{t} \\
S G F_{t}=0.05+0.01 \times \sin (3.14(\text { Time }-1978)) \\
C C_{t}=0.02+0.05 \sin (3.14(\text { Time }-1978)) \\
I D 3_{t}=I D 3_{\mathrm{r}-1}+\int_{t-1}^{t}\left(I P_{t}-\text { DELAY } 3\right) d t
\end{gathered}
$$




\section{Empirical Analysis}

\subsection{Equation and Parameters Determination}

In order to determine every system parameter more accurate, parameters of the model are set by using Beijing data from 1978 to 2011 which is borrowed from Beijing Statistical Yearbook.

(1) GDP self-growth coefficient (GGC)

GDP growth is affected by the capital, labor and technology. From historical data, it is found that the overall trend of GDP is rising. $y_{k}$ expresses the amount of GDP at the year of $k$. The growth coefficient of GDP at the year of $k+1$ is denoted by Equation 23 .

$$
\zeta_{k+1}=\frac{y_{k+1}}{y_{k}}
$$

GGC can be expressed by the table function in the Vensim -PLE, which is shown as follows. GGC $=([(1978,0)(2028,0.316)],(1978,0),(1979,0.154),(1980,0.158),(1981,0.0007)$, $(1982,0.157),(1983,0.182),(1984,0.183),(1985,0.187),(1986,0.108),(1987,0.147)$ ， $(1988,0.255),(1989,0.01),(1990,0.098),(1991,0.196),(1992,0.184),(1993,0.25)$, $(1994,0.292),(1995,0.316),(1996,0.187),(1997,0.161),(1998,0.144),(1999,0.126)$ ， $(2000,0.18),(2001,0.173),(2002,0.164),(2003,0.16),(2004,0.205),(2005,0.155)$ ， $(2006,0.165),(2007,0.13),(2008,0.129),(2009,0.093),(2010,0.1),(2011,0.081),(2012,0.077)$, $(2013,0.05),(2015,0.05),(2018,0.05),(2020,0.05),(2024,0.05),(2026,0.05),(2028,0.05))$.

\section{(2) Logistics cost}

The logistics cost factor is an important indicator which reflects the logistics cost produced by per unit logistics quantity. In the light of historical data of social logistics total costs and GDP, the proportion of social logistics making up for GDP can be calculated. Logistics cost is affected by the supply and demand ratio. This means that the ratio increases, the logistics cost reduces. Conversely, the ratio reduces, and the cost increases. Take all these into considerations, the cost factor of the model is as follow. Logistics costs $=([(0,0)-(2,1)]$, $(0,0.25),(0.5,0.015),(1,0.0075),(2,0.0050)$. 


\section{(3) Logistics industry investment proportion table}

The logistics industry investment includes transportation, warehousing, postal services, wholesale trade, retail, trade services investment as well as logistics talent training investment etc. To ensure the data consistency, this paper applies the proportion of transportation and post investment proportion of GDP to determine the logistics industry investment proportion table. The specific table function is as below. Logistics industry investment proportion table

$$
\begin{aligned}
& =([(1978,0.0142)(2028,0.0714)],(1978,0.0193),(1979,0.0174),(1980,0.0194), \\
& (1981,0.0158),(1982,0.0142),(1983,0.0175),(1984,0.0157),(1985,0.0206),(1986,0.0232), \\
& (1987,0.0297),(1988,0.019),(1989,0.0219),(1990,0.0272),(1991,0.0217),(1992,0.04), \\
& (1993,0.0583),(1994,0.0709),(1995,0.0543),(1996,0.0556),(1997,0.0546),(1998,0.0714), \\
& (1999,0.0404),(2000,0.0393),(2001,0.04),(2002,0.0449),(2003,0.0431),(2004,0.0363), \\
& (2004.15,0.0375316),(2005,0.0443),(2006,0.0645),(2007,0.0641),(2008,0.063), \\
& (2009,0.0681),(2010,0.066),(2011,0.04),(2012,0.05),(2020,0.05),(2028,0.055)) .
\end{aligned}
$$

\section{(4) The other parameters determination}

There are many methods to determine the parameters in the system dynamics model, such as the observational method, empirical method, fitting method, estimation method and experimental optimization method (Yin, Xie \& Guo, 2013). Some parameters in the social economic system are difficult to get an accurate calculation due to many influential factors. Only by referring empirical data and making adjustment in the process of solution are parameters set. The other parameters in this model are set by referring research ideas, parameter determination methods and individual empirical parameters which are shown in Table 1.

\begin{tabular}{|c|c|}
\hline Parameter variables & Value \\
\hline Investment effect coefficient & 0.7 \\
\hline Investment conversion rate (tons/one hundred million) & 30 \\
\hline Ideal demand coefficient & 0.015 \\
\hline Initial value of the regional GDP (one hundred million) & 108.8 \\
\hline Initial of logistics supply capacity(ten thousand tons) & 4563 \\
\hline INITIAL TIME & 1978 \\
\hline FINAL TIME & 2028 \\
\hline TIME STEP & 1 \\
\hline
\end{tabular}

Table 1. Other Parameters' Value 


\subsection{Validation of System Dynamics}

Before the policy simulation, we should test the model validation. The purpose of the validation is to verify the similarity of model and reality system. This means testing whether the model can reflect the features and changes of the actual system and whether we can correctly understand the problem to be solved. The methods are structural testing, parametric tests and behavior tests.

During the model validation process, comparing the simulation result and historical data is needed to test model accuracy. As shown in Tables 2.1, 2.2 and 2.3, comparison between simulation values and actual values is counted in Beijing from 1978-2011. From the table, it can be concluded that most errors are controlled within 5\%, which indicates that the simulation results is consistent with the actual value.

\begin{tabular}{|l|c|c|c|c|c|c|c|c|c|c|c|c|}
\hline \multicolumn{1}{|c|}{ Year } & 1978 & 1979 & 1980 & 1981 & 1982 & 1983 & 1984 & 1985 & 1986 & 1987 & 1988 & 1989 \\
\hline Initial value & 108.8 & 120.1 & 139.1 & 139.2 & 154.9 & 183.1 & 216.6 & 257.1 & 284.9 & 326.8 & 410.2 & 456.0 \\
\hline Predictive value & 108.8 & 110.8 & 129.9 & 152.5 & 154.8 & 181.4 & 217.0 & 259.5 & 311.1 & 348.0 & 402.7 & 473.0 \\
\hline Error value (\%) & 0.00 & -7.71 & -6.62 & 9.53 & -0.10 & -0.90 & 0.21 & 0.95 & 9.19 & 6.47 & -1.82 & 3.72 \\
\hline
\end{tabular}

Table 2.1. Simulation Effect Testing of Regional GDP State Variables Unit: 100million

\begin{tabular}{|l|c|c|c|c|c|c|c|c|c|c|c|c|}
\hline \multicolumn{1}{|c|}{ Year } & 1990 & 1991 & 1992 & 1993 & 1994 & 1995 & 1996 & 1997 & 1998 & 1999 & 2000 & 2001 \\
\hline Initial value & 500.8 & 598.9 & 709.1 & 886.2 & 1145.3 & 1507.7 & 1789.2 & 2077.1 & 2377.2 & 2678.8 & 3161.7 & 3708.0 \\
\hline Predictive value & 520.0 & 576.1 & 694.0 & 847.0 & 1039.3 & 1449.1 & 1782.2 & 2122.7 & 2471.9 & 2785.4 & 3200.1 & 3783.1 \\
\hline Error value (\%) & 3.83 & -3.81 & 2.13 & 4.42 & 0.57 & 3.89 & 0.39 & 2.20 & 3.98 & 3.98 & 1.21 & 2.03 \\
\hline
\end{tabular}

Table 2.2. Simulation Effect Testing of Regional GDP State Variables (continue) Unit: 100 million

\begin{tabular}{|l|c|c|c|c|c|c|c|c|c|c|}
\hline \multicolumn{1}{|c|}{ Year } & $\mathbf{2 0 0 2}$ & $\mathbf{2 0 0 3}$ & $\mathbf{2 0 0 4}$ & $\mathbf{2 0 0 5}$ & $\mathbf{2 0 0 6}$ & $\mathbf{2 0 0 7}$ & $\mathbf{2 0 0 8}$ & $\mathbf{2 0 0 9}$ & $\mathbf{2 0 1 0}$ & $\mathbf{2 0 1 1}$ \\
\hline Initial value & 4315.0 & 5007.2 & 6033.2 & 6969.5 & 8117.8 & 9846.8 & 11115.0 & 12153.0 & 14113.6 & 16251.9 \\
\hline Predictive value & 4444.6 & 5180.2 & 6015.9 & 7255.8 & 8387.3 & 9777.0 & 11053.6 & 12485.2 & 13652.7 & 15922.9 \\
\hline Error value (\%) & 3.00 & 3.45 & 0.29 & 4.11 & 3.32 & 0.71 & 0.55 & 2.73 & 3.27 & 2.02 \\
\hline
\end{tabular}

Table 2.3. Simulation Effect Testing of Regional GDP State Variables (continue) Unit: 100 million

\subsection{The Policy Simulation Programs and Results Analysis}

Based on the system dynamic simulation of regional logistics in Beijing, the interactive relationship between logistics industry policy and regional economy is found by adjusting parameters of the model, and get hold of the policy measures which is suitable for the development of the logistics system in the Beijing area. Thus, we simulate the model through 
changing technical input efficiency, increasing investment in fixed assets, adjusting industrial structure and comprehensive policy.

\section{(1) Policy I: Change the technology investment efficiency}

Essentially, the technology policy is to improve the rational allocation of resource elements by changing the investment conversion rate. With economic development, the international competitiveness of industry is stepping into innovation-driven stage after experiencing a factor-driven and capital-driven stage. The reasonable input of new technologies and new programs enhance the investment transformation effect. In this paper, we will change the investment conversion from 30 to 50 to analyze other variables of the system.

(2) Policy II: Increase the investment in fixed assets

Increasing investment in fixed assets refers to perfect the logistics infrastructure construction so as to provide a good development environment for the logistics industry. This paper designs the proportion of fixed assets investment to increase by $2 \%$ to analyze other variables of the system.

\section{(3) Policy III: Adjusting industrial structure}

The industrial structure policy means the priority selection of the industry development. It is made by government through affecting industrial structure transformation to achieve the optimization of the industrial structure and accelerate economic growth. According to the historical data analysis, the industrial structure of Beijing is constantly changing. The proportion of primary industry has declined year by year. In contrary, the proportion of tertiary industry has increased. Therefore, this paper makes the proportion of the first, second and tertiary industry $1 \%, 24 \%$ and $75 \%$ respectively.

\section{(4) Policy IV: Comprehensive policy}

This policy combines changing technical input efficiency policy, increasing investment in fixed assets policy, adjusting industrial structure policy. The investment conversion rate and the industry structure are adjusted according to the Policy I and Policy III. The proportion of fixed assets investment is increased by $0.5 \%$. 
Parameters of Policy I, Policy II,Policy III and Policy IV are put into model and simulated by running Vensim-PLE. Results of sensitivity analysis including GDP, logistics demand, logistics supply capacity and actual logistics costs are as follows.

For GDP, comparing simulation results, the conclusion is that Policy IV has the best pull effect for the GDP, the Policy I and the Policy II make a better performance than Policy III, and the Policy I has better effect than the Policy II and the Policy III. The result demonstrates that resources can be rationally allocated by altering technology investments conversion rate and then GDP growth can greatly be promoted by the reasonable investment of the new technology and new program. In addition, social economic development is boosted after logistics demand is met by improving logistics supply capacity which is modified by increasing the fixed assets investment. With industry structure getting more rational in Beijing, the impact of adjusting the proportion of industry structure on GDP is not obvious.

For the logistics demand, after the Policy IV implementation, the logistics demand is increased. After the Policy I and II implementation, the logistics demand is slightly increased, however, after the Policy III implementation, the logistics demand is reduced. These indicate that the industry structure of Beijing has transformed from industrial-oriented to service-oriented. At the same time, the logistics demand is to improve the service requirement after that logistics operation efficiency and the information level should be enhanced to accelerate the logistics industry.

For the logistics supply, the effect of the above four policies for logistics supply capacity is Policy IV > Policy I > Policy II > Policy III, which means the mixed effect of Policy IV is much better than the separate effect of PolicyI II and III. Take the single policy into consideration, the impact of Policy III on the logistics supply capacity is not obvious. Thus, increasing the investment conversion rate and fixed assets investment will improve the logistics supply capacity. However, the adjustment of the industry structure will not generate the same obvious effect.

With the increasing of logistics demand, actual logistics costs shows upwards trend under four policies, however, different policy has different effect. Overall, the impact of Policy IV on actual logistics costs is much better than the others. For the single policy, the impact of Policy I on the actual logistics costs is much better than Policy II and Policy III. Through changing the investment conversion rate and fixed assets investment proportion, the actual logistics cost have been significantly reduced. Meanwhile, due to the adjustment of industrial structure, logistics demand reduces, the impact of Policy II on the actual logistics costs is higher than Policy III. In the short term, the impact of changing the investment conversion efficiency and increasing the fixed assets investment on the actual logistics costs is much better than adjusting industry structure by comparing the effect. Nevertheless, in the long term, adjusting 
the industry structure will have a profound impact on the actual logistics costs and regional GDP.

In summary, comparing the four policies on GDP, logistics demand, logistics supply capacity and logistics cost, we find Policy IV is much better than the others. Therefore, influential factors of logistics industry should be comprehensively considered and developed reasonably and assertively. Only by this way will the high return be obtained with lower cost.

\section{Conclusions}

In view of the dynamic relationship between logistics industry development policy and region economy, the correlation is deeply analyzed and the dynamic model of logistics industry development policy is built. Logistics industry development policy of Beijing including changing the technology investment efficiency, increasing the fixed assets investments, adjusting the industry structure and comprehensive policy are simulated after the validity check. The following conclusion can be obtained through policy simulation and theoretical analysis. Above all, the supply capacity is less than logistics demand in the Beijing area. Logistics industry development policies have obvious role in promoting economic growth and improving logistics efficiency. Besides, from the effect of single policy, the policy of technology investment efficiency has better effect for GDP, logistics demand and actual logistics cost than other policies. Increase the investment in fixed assets has the best pull effect for the logistics supply capacity. Finally, from the comprehensive effect of policies, the effect of the comprehensive policy is significantly better than the effect of single policy.

As part of the logistics data is difficult to obtain, some data is replaced with related parameters, and what makes the prediction accuracy of the model lower. In the future, a more accurate model equation needs to be built and more accurate system parameters need to be designed so as to make up for the deficiencies.

\section{Acknowledgments}

This paper was funded by National Natural Science Foundation of China (No. 71273023)

\section{References}

Cao, P., \& Chen, F.J. (2012). Grey BP Neural Networks Model based on GA and Its Application in Regional Logistics Demand Forecasting. Journal of Beijing Institute of Technology (Social Sciences Edition), 14(3), 66-70. 
Dilek, Ö. (2012). Strategic choice for Istanbul: A domestic or international orientation for logistics? Cities, 27, 154-163.

Hai, F., Zhang, L.L., \& Sun, S.S. (2005). Research on modern logistics industrial policy system in China. Wuhan university Journal (Philosophy and social science), 58, 639-644.

Hens, R., Robvan, D., \& Hei, C. (2011). Public policy intervention in freight transport costs: effects on printed media logistics in the Netherlands. Transport Policy, 12, 35-46.

Jin, L. (2012). Research on the Policy of Modern Logistics Industry Development in Henan. Logistics Engineering and management, 34, 10-12.

Li, Z.B., Hu, B.M., \& Meng, X.S. (2009). The Development Situation and Suggestions of Modern Logistics Industry of Hebei Province. Proceedings of International Conference on Management and Service Science, MASS, Tianjin (China), 20-22 Sep.

Liu, Z., Li, Y., Dai, W., \& Zhang, R.T. (2013). Current situation and countermeasures of port logistics park information construction. Journal of industrial engineering and management, 6(1), 227-236. http://dx.doi.org/10.3926/jiem.676

Magnus, A., \& Ruth, B. (2010). The implications of deregulation \& liberalization on the logistics service industry in Lao PDR. International Journal of Production Economics, 128(1), 68-76. http://dx.doi.org/10.1016/j.ijpe.2009.08.028

Masahiro, H. (2010). The evolution of logistics policy in Japan. China Business and Market, 24(3), 4-7.

Muñuzuri, J., Cortés, P., Guadix, J., \& Onieva, L. (2012). City logistics in Spain: Why it might never work. Cities, 29(2), 133-141. http://dx.doi.org/10.1016/j.cities.2011.03.004

Pilar, L., González, B., Adenso, D., \& Hakim, A. (2004). Environmental and reverse logistics policies in European bottling and packaging firms. International Journal of Production Economics, 88(1), 95-104. http://dx.doi.org/10.1016/S0925-5273(03)00181-6

Wang, Q.F. (2009). System Dynamic. Shanghai: Shanghai University of Finance and Economics Press.

Yin, J.J., Xie, Z.Z., \& Guo, J.J. (2013). Study on the Real Estate Credit Risk Based on System Dynamics.Journal of System and Management Sciences, 3(1), 31-36. http://www.aasmr.org/jsms/Vol3/No1/JSMS Vol3_No1_5.pdf

Journal of Industrial Engineering and Management, 2014 (www.jiem.org)

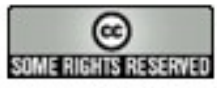

Article's contents are provided on a Attribution-Non Commercial 3.0 Creative commons license. Readers are allowed to copy, distribute and communicate article's contents, provided the author's and Journal of Industrial Engineering and Management's names are included. It must not be used for commercial purposes. To see the complete license contents, please visit http://creativecommons.org/licenses/by-nc/3.0/. 